\title{
Cytokine Production in Cholangiocarcinoma Cells in Response to Clonorchis sinensis Excretory-Secretory Products and Their Putative Protein Components
}

\author{
Jhang Ho Pak, , Ji-Yun Lee', Bo Young Jeon ${ }^{1}$, Fuhong Dai, ${ }^{2,3}$, Won Gi Yoo², Sung-Jong Hong ${ }^{2, *}$ \\ ${ }^{1}$ Department of Convergence Medicine, University of Ulsan College of Medicine and Asan Institute for Life Sciences, Asan Medical Center, Seoul \\ 05505, Korea; ' 2 Department of Medical Environmental Biology, Chung-Ang University College of Medicine, Seoul 06987, Korea; ${ }^{3}$ Department of \\ Parasitology, School of Biology and Basic Medical Sciences, Medical College, Soochow University, 199 Ren-ai Road, Suzhou Industrial Park, \\ Suzhou, Jiangsu 215123, P.R. China
}

\begin{abstract}
Clonorchis sinensis is a carcinogenic human liver fluke that promotes hepatic inflammatory environments via direct contact or through their excretory-secretory products (ESPS), subsequently leading to cholangitis, periductal fibrosis, liver cirrhosis, and even cholangiocarcinoma (CCA). This study was conducted to examine the host inflammatory responses to $C$. sinensis ESPs and their putative protein components selected from $C$. sinensis expressed sequenced tag (EST) pool databases, including TGF- $\beta$ receptor interacting protein 1(CsTRIP1), legumain (CsLeg), and growth factor binding protein 2 (CsGrb2). Treatment of CCA cells (HuCCT1) with the ESPs or bacterial recombinant $C$. sinensis proteins differentially promoted the secretion of proinflammatory cytokines (IL-1 $\beta$, IL-6, and TNF- $\alpha$ ) as well as anti-inflammatory cytokines (IL-10, TGF- $\beta 1$, and TGF- $\beta 2$ ) in a time-dependent manner. In particular, recombinant $C$. sinensis protein treatment resulted in increase (at maximum) of $\sim 7$-fold in TGF- $\beta 1, \sim 30$-fold in TGF- $\beta 2$, and $\sim 3$-fold in TNF-a compared with the increase produced by ESPs, indicating that CsTrip1, CsLeg, and CsGrb2 function as strong inducers for secretion of these cytokines in host cells. These results suggest that $C$. sinensis ESPs contribute to the immunopathological response in host cells, leading to clonorchiasis-associated hepatobiliary abnormalities of greater severity.
\end{abstract}

Key words: Clonorchis sinensis, excretory-secretory products, recombinant Cs-driven protein, host immune response, inflammatory cytokine

\section{INTRODUCTION}

Helminth infection induces host immune responses, including production of diverse cytokines, through activation of the innate and adaptive inflammatory systems. There are 2 stages of inflammation, acute and chronic. Acute inflammation is the initial stage of the host immune response during which tissue lesions are repaired or pathogens eliminated. It lasts only for a short time and is beneficial for the host to restore the normal physiological homeostatic state. If the inflammation lasts for a longer period of time, however, chronic inflammation sets in and may predispose the host to more severe chronic diseases, including increased risk of cancer. Inflammatory cytokines are expressed in inflamed tissues by resident or

\footnotetext{
- Received 4 July 2019, revised 27 July 2019, accepted 1 August 2019.

*Corresponding authors (jhpak@amc.seoul.kr; hongsj@cau.ac.kr) (C) 2019, Korean Society for Parasitology and Tropical Medicine This is an Open Access article distributed under the terms of the Creative Commons Attribution Non-Commercial License (http://creativecommons.org/licenses/by-nc/4.0) which permits unrestricted non-commercial use, distribution, and reproduction in any medium, provided the original work is properly cited.
}

infiltrating cells on proinflammatory stimulation. Their functions are mediated by binding to specific receptors expressed on the surface of target cells, in which they can have opposite effects on the parasite; either control of the infection or promotion of the disease. Inflammatory cytokines are generally classified as proinflammatory (IL-1, IL-4, IL-6, IL-12, IL-15, IL17, IL-23, TNF- $\alpha$, and IFN- $\alpha$ ) or anti-inflammatory (IL-10 and TGF- $\beta$ ) $[1,2]$.

Clonorchiasis, human infection by Clonorchis sinensis, is an endemic trematodiasis prevalent predominantly in the East Asian countries, where it constitutes a major and current health problem. It is estimated that more than 200 million people worldwide are at the risk of infection, 15-20 million are infected, and 1.5-2 million have symptoms [3]. The pathogenesis of clonorchiasis includes mechanical obstruction of the bile ducts by the worms, physical injury of the bile duct epithelium by worm feeding and migrating activities, and chemical irritation by their excretory-secretory products (ESPs). These combined factors provoke various primary and secondary pathophysiological changes in the bile ducts and sur- 
rounding liver tissues such as inflammation, hyperplasia of epithelial cells, metaplasia in the mucosa, and periductal fibrosis. Complications associated with clonorchiasis depend on the duration of infection, worm burden, location of the worms, and the susceptibility of the host $[4,5]$. Based on etiological and experimental evidence as well as case-control studies, C. sinensis, together with Opisthorchis viverrini, has been classified as a Group 1 biological human carcinogen by the International Agency for Research on Cancer [6].

Proteins and other metabolites are continuously excreted and secreted from the tegument, oral opening, and gut of liver flukes into their extracellular surroundings, and these play pivotal roles in host-parasite interactions. Cells exposed to C. sinensis ESPs display diverse pathological responses including proliferation and inflammation $[7,8]$. Differential transcriptional and proteomic profiling of ESP-treated cholangiocarcinoma cells (HuCCT1) showed that regulated genes/proteins were involved in apoptosis, carcinogenesis, metabolism, redox homeostasis, and signal transduction, evidencing multiple roles for ESPs in the pathological processes in the host cells $[9,10]$. An immunogenic feature of O. viverrini ESPs is reported to be their internalization in cholangiocytes via endocytotic pathways, contributing to immune-mediated pathogenesis including an increase in cell proliferation and IL-6 production [11]. Moreover, individual components of ESP proteins cloned and characterized from $C$. sinensis and $O$. viverrini, including legumain (CsLeg) [12], granulin (CsGrn) [13], granulin-like growth factor (OvGrn-1) [14], and thioredoxin (OvTrx-1) [15], have been shown to function as potential antigens in the hosts. These findings suggest that liver fluke ESPs stimulate host cellular immune responses, leading to subsequent hepatic pathogenesis.

We searched for suitable candidate genes/proteins involved in cell proliferation and inflammation using the National Center for Biotechnology Information (PubMed database, http://www.ncbi.nlm.nih.gov) website. The selections were then employed as probes for further mining C. sinensis expressed sequence tag (EST) pool databases (http://chimp. kribb.re.kr/pipeline2/) established by the Korea Research Institute of Bioscience \& Biotechnology. After considering potential protein components of $C$. sinensis ESPs, growth factor receptorbound protein 2 (CsGrb2) and TGF- $\beta$ receptor interacting protein 1 (CsTrip1) as well as legumain (CsLeg) were finally selected as candidate proteins to examine host immune response such as inflammation. It has been reported that these recombinant proteins immunoreact with the sera of clonorchiasis patients $[12,16,17]$.

In the context of the immunopathological roles of C. sinensis ESPs in host cells, the present study profiled the differential expressions of inflammatory cytokines in ESP-treated HuCCT1 cells. We also examined whether ESP-induced cytokine regulation was differentially modulated in HuCCT1 cells treated with recombinant $\mathrm{Cs}$ proteins that were putative components of the ESPs. Our results indicate that the ESPs are highly immunogenic, interacting with biliary epithelia to stimulate inflammatory responses.

\section{MATERIALS AND METHODS}

\section{Materials}

Cell culture medium components were purchased from Life Technologies (Grand Island, New York, USA). A bacterial expression plasmid of CsLeg was kindly provided by Dr. JungWon Ju of the Division of Vectors \& Parasitic Diseases, Korean Centers for Disease Control and Prevention, Osong, Korea. All other chemicals (biotechnology grade) were from Sigma-Aldrich (St. Louis, Missouri, USA).

\section{Cloning of a gene encoding CsTrip1}

The cDNA sequence information of CsTrip1 (GenBank accession number, AAY32924), retrieved from the C. sinensis EST database (http://chimp.kribb.re.kr/pipeline2/), contains a 984bp open reading frame. The EST clone was obtained from $C$. sinensis transcriptome glycerol stock as described previously [18]. This EST clone (clone number CSE05971) was found to be a partial clone in which a 153-bp section was deleted from the $5^{\prime}$ end (51 amino acids were missing from the N-terminus). To obtain the full-length of the coding sequence, sequential PCR was performed using 3 sets of primers and CDNAs synthesized from adult worm total RNA as a template, followed by subcloning PCR products into pRSETA vector (In-fusion cloning kit; Clontech, Palo Alto, California, USA). Sequencing of the recombinant plasmid (pRSET-CsTrip1) validated that the insert of CsTrip1 was in frame to the tag protein.

\section{Expression and purification of Cs recombinant proteins}

The pRSET-CsTrip1 was transformed into Escherichia coli strain BL21(DE3)pLysS. Expression of the recombinant fusion protein was induced by isopropyl-D-thiogalactosidase (IPTG) at a final concentration of $1 \mathrm{mM}$ for $4 \mathrm{hr}$ at $37^{\circ} \mathrm{C}$. The fusion 
protein was purified under denaturing conditions using $8 \mathrm{M}$ urea, refolded, and loaded on a Ni-NTA affinity column (Qiagen Inc., Hilden, Germany) according to the manufacturer's instructions. The expression and purification of recombinant CsGrb2 and CsLeg proteins was performed as described previously $[12,16]$. The expression of each recombinant protein was determined by SDS-PAGE with subsequent Coomassie brilliant blue staining. Purified proteins were further dialyzed into phosphate-buffered saline (PBS), and residual endotoxin including lipopolysaccharide was removed using an Endotoxin Removal Spin Column (Pierce Biotechnology, Rockford, Illinois, USA). The protein concentration was measured using DC Protein Assays (Bio-Rad, Hercules, California, USA), and the protein aliquots were stored at $-80^{\circ} \mathrm{C}$ until use.

\section{Cell culture and ESP or recombinant Cs protein treatment}

C. sinensis ESPs were prepared as described previously [8]. The human cholangiocarcinoma cells, HuCCT1, were cultured in RPMI 1640 medium supplemented with 10\% fetal bovine serum (FBS) and an antibiotic mixture at $37^{\circ} \mathrm{C}$ in a humidified $5 \% \mathrm{CO}_{2}$ incubator. For ESP or recombinant Cs protein treatment, cells were seeded at $~ 80 \%$ confluence in 24 -well culture dishes and grown for $24 \mathrm{hr}$ under standard culture conditions. Cells were gradually deprived of serum by incubation in $2 \%$ FBS overnight, followed by incubation in serum free medium for $3 \mathrm{hr}$. These serum-starved cells were treated with ESPs (800 $\mathrm{ng} / \mathrm{ml})$ or recombinant Cs proteins $(2 \mu \mathrm{g} / \mathrm{ml})$ and incubated for $1,3,9,15$, and $24 \mathrm{hr}$.

\section{Cytokine assay}

Immunoreactive human IL-1 $\beta$, IL-2, IL-6, IL-10, TNF- $\alpha$, TGF- $\beta 1$, TGF- $\beta 2$, and INF- $\gamma$ were quantitated in untreated, ESP, or each Cs recombinant protein-treated culture supernatants at indicated times using commercially available Quantikine ELISA kits (R\&D Systems; Minneapolis, Minnesota, USA) according to the manufacturer's instructions. The level of each cytokine was calculated from its standard curve using human recombinant cytokines provide by the manufacturer. The absorbance was measured at $450 \mathrm{~nm}$ using a micro-ELISA reader (Spectra MAX340PC, Molecular Devices LLC, San Jose, California, USA).

\section{Statistical analyses}

Data are expressed as mean \pm S.D. of 3 or more independent experiments. Statistical significance was evaluated by 1-way
ANOVA, followed by a Student's $t$-test or Bonferroni's test, as appropriate. Differences in mean values were considered statistically significant at $P<0.05$.

\section{RESULTS}

\section{Expression of recombinant CsTrip1, CsLeg, and CsGrb2 in bacterial cells}

The bacterially expressed recombinant CsTrip1 protein (theoretical molecular weight; $\sim 36 \mathrm{kDa}$ ) fused with $6 \times$ histidine tag at $\mathrm{N}$-terminus was purified under denaturing conditions with $8 \mathrm{M}$ urea. After dialyzing against gradually decreased urea solution, recombinant protein was precipitated due to its high concentration, and removed by centrifugation. Recombinant CsTrip1 appeared as a single band with a molecular weight of 41 kDa on SDS-PAGE (Fig. 1A). This purified CsTrip1 protein was used to treat HuCCT1 cells.

The recombinant CsLeg protein without the signal peptide was found to be expressed in the pellet of the bacterial lysate. The pellet was washed twice with ice-cold PBS to remove impurities and was resolved in $8 \mathrm{M}$ urea to purify under denaturing conditions. The purified protein migrated as predicted with a molecular weight of $\sim 49.5 \mathrm{kDa}$ under reducing SDSPAGE (Fig. 1B). This CsLeg protein was used as a stimulant for inflammatory response to HuCCT1 cells.

Recombinant CsGrb2 protein was produced as a fusion protein to Sj26GST with whole molecular mass of $60 \mathrm{kDa}$ as previously reported [16]. This fusion protein is tightly bound in a GSH-sepharose 4B column. On-bead cleavage with thrombin treatment resulted in the release of high purity $\mathrm{CsGrb} 2$ protein (34 kDa) into the PBS elute (Fig. 1C). This recombinant protein was used in a subsequent experiment described below.

\section{Differential expression of cytokines in ESP-treated HuCCT1 cells}

We examined differential secretions of cytokines in C. sinensis ESP-treated HuCCT1 cells during a 24-hr period, as assessed by ELISA assays. As shown in Fig. $2 \mathrm{~A}$, the level of IL-1 $\beta$ secretion was significantly increased in cells treated with ESPs for 3 $\mathrm{hr}$, reached a maximum at $9 \mathrm{hr}$, and gradually declined thereafter, though remaining -3-fold higher than the level at $0 \mathrm{hr}$. The levels of IL- 6 and TGF- $\beta 2$ secretion increased continuously in proportion to the exposure time (Fig. 2C, F). An elevated level of IL-10 was detected as early as $1 \mathrm{hr}$ after ESP treatment and was continuously maintained up to $24 \mathrm{hr}$ (Fig. 2D). The se- 

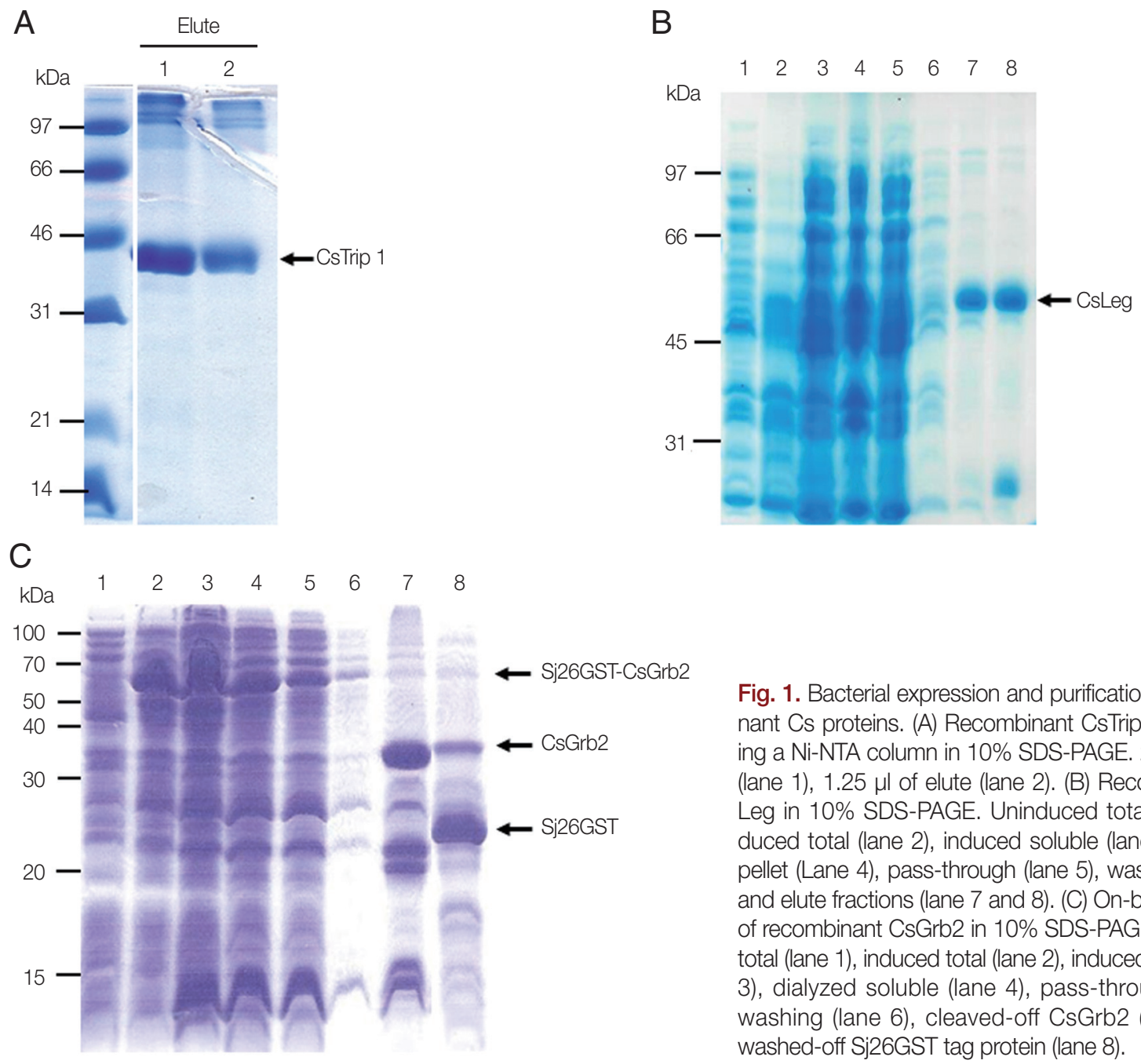

Fig. 1. Bacterial expression and purification of recombinant Cs proteins. (A) Recombinant CsTrip1 purified using a Ni-NTA column in 10\% SDS-PAGE. $2.5 \mu \mathrm{l}$ of elute (lane 1), $1.25 \mu \mathrm{l}$ of elute (lane 2). (B) Recombinant CsLeg in 10\% SDS-PAGE. Uninduced total (lane 1), induced total (lane 2), induced soluble (lane 3), induced pellet (Lane 4), pass-through (lane 5), washing (lane 6), and elute fractions (lane 7 and 8). (C) On-bead cleavage of recombinant CsGrb2 in 10\% SDS-PAGE. Uninduced total (lane 1), induced total (lane 2), induced soluble (lane 3), dialyzed soluble (lane 4), pass-through (lane 5), washing (lane 6), cleaved-off CsGrb2 (lane 7), and washed-off Sj26GST tag protein (lane 8).

cretion of TGF- $\beta 1$ and TNF- $\alpha$ increased relatively later, at $15 \mathrm{hr}$ and $9 \mathrm{hr}$, respectively, with maximal levels at $24 \mathrm{hr} \sim 4$-fold and 8-fold higher, respectively, than those at $0 \mathrm{hr}$ (Fig. 2E, G). There were no obvious changes in the levels of IL- 2 and IFN- $\gamma$ secretion during the 24-hr exposure time (Fig. 2B, H). These results indicate that the ESPs promoted the production of IL-1 $\beta$, IL-6, IL-10, TNF- $\alpha$, and TGF- $\beta$ isoforms in HuCCT1 cells.

\section{Differential secretion of cytokines in recombinant Cs protein-treated HuCCT1 cells}

Because of a significant but slight increase in IL-10 secretion $(\sim 1.8 \mathrm{pg} / \mathrm{ml})$ and constant levels of IL-2 and IFN- $\gamma$ in response to the ESPs, we focused only on the regulation of ESP-induced cytokines in recombinant Cs protein-treated HuCCT1 cells. The levels of IL- $1 \beta$ secretion in each batch of recombinant protein-treated cells gradually increased between $3 \mathrm{hr}$ and 15 hr, and the maximal levels were maintained at $24 \mathrm{hr}$ (Fig. 3A). Gradual increases in IL-6 secretion occurred in a time-dependent manner with a significant elevation after $3 \mathrm{hr}$ treatment (Fig. 3B). A significant elevation of TGF- $\beta 1$ was detected as early as $1 \mathrm{hr}$ after treatment (except for that of CsTrip1) and continued up to $24 \mathrm{hr}$, while the elevation of TGF- $\beta 2$ was delayed until 2 hr later than the TGF- $\beta 1$ increment (except for CsGrb2) with further proportional increases with exposure time (Fig. 3C, D). TNF- $\alpha$ was a relatively late-responding cytokine in HuCCT1 cells; significant secretion with CsTrip or CsLeg occurred at $9 \mathrm{hr}$ and reached a maximum at $24 \mathrm{hr}$, while significant secretion with CsGrb2-treated cells started at $3 \mathrm{hr}$ (Fig. 3E). Of note, the maximum levels of TGF- $\beta 1$ and TGF- $\beta 2$ induced by Cs proteins at 24 hr were 7- and 31-fold higher, respectively, than those of the ESPs ( $\sim 250 \mathrm{vs} \sim 35 \mathrm{pg} / \mathrm{ml}$ and $\sim 1,200$ vs $\sim 38 \mathrm{pg} / \mathrm{ml}$, respectively). The level of TNF- $\alpha$ produc- 
A

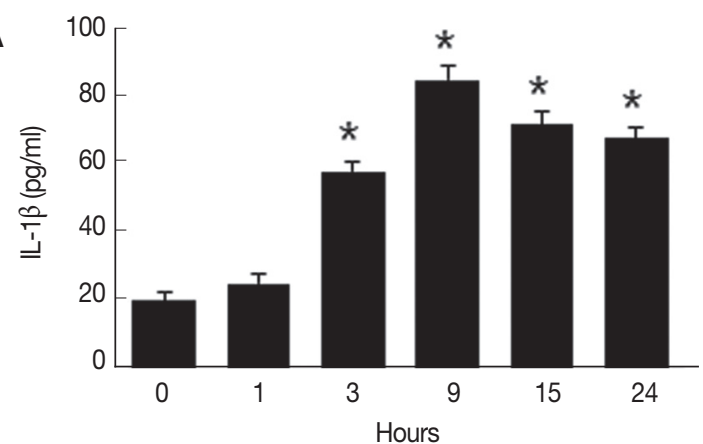

C

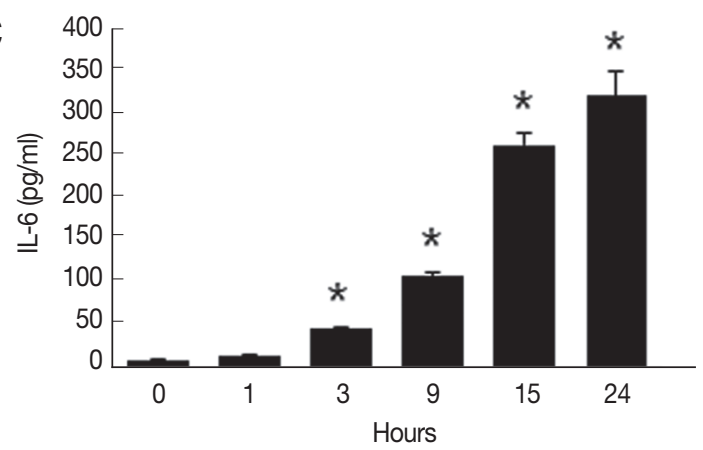

$E$

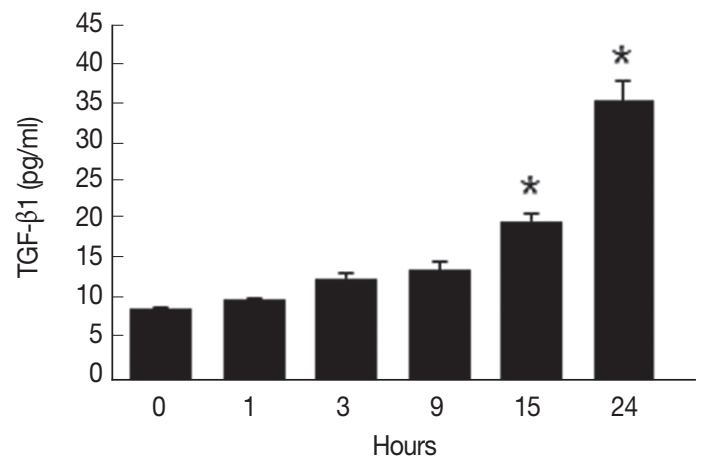

G

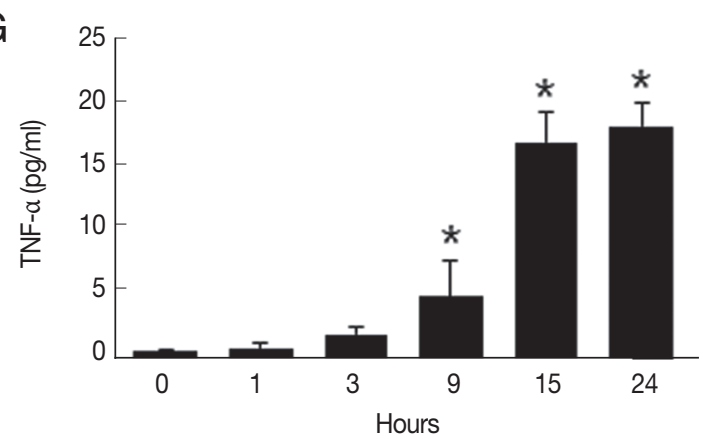

B

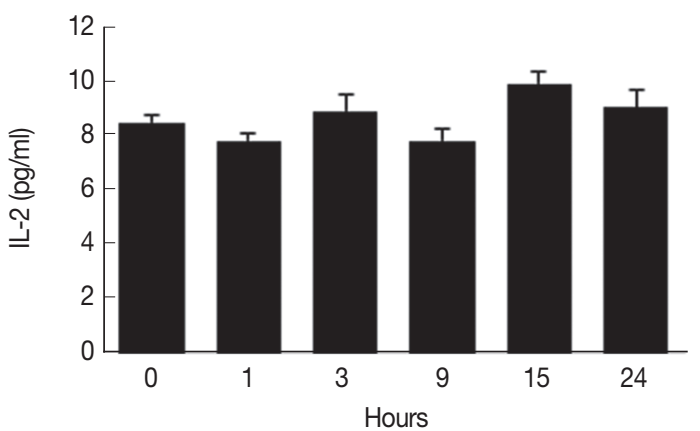

D

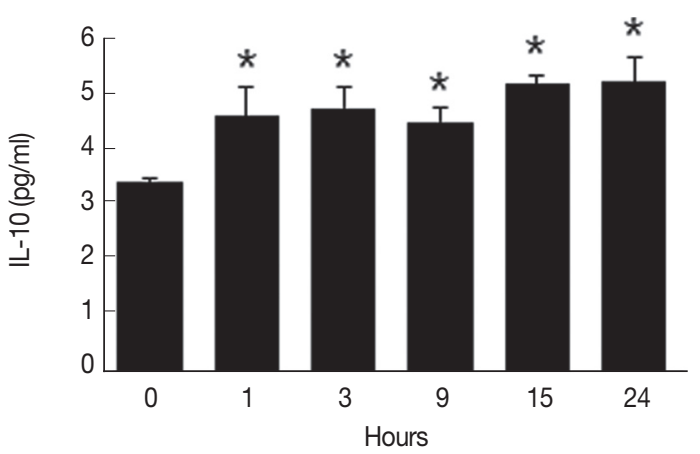

$\mathrm{F}$

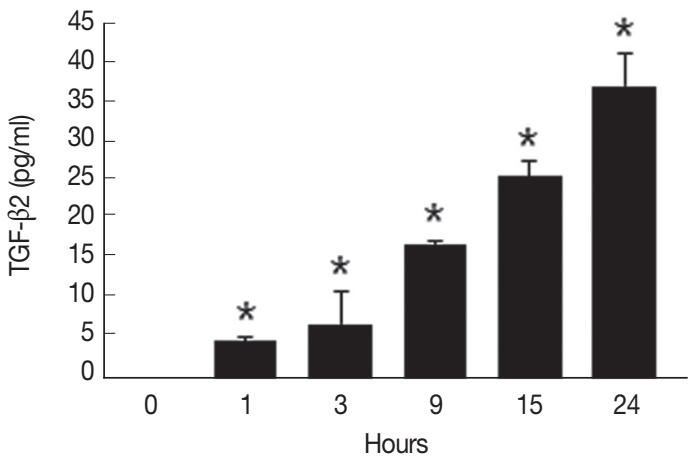

$\mathrm{H}$

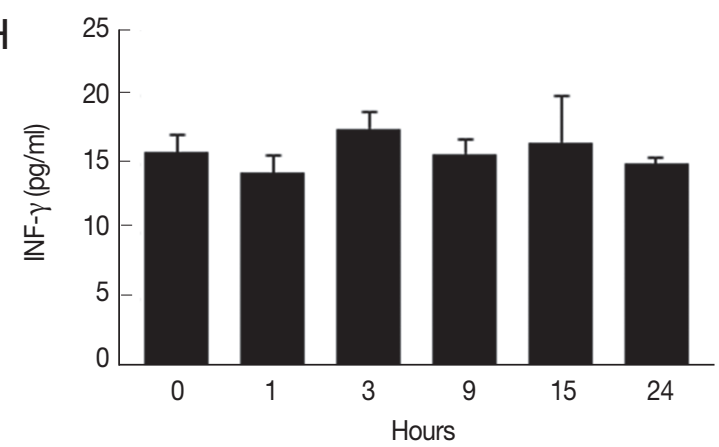

Fig. 2. Proinflammatory cytokine profiling of HuCCT1 cells in response to C. sinensis ESPs. After 0-24 hr ESP treatment (800 $\mathrm{ng} / \mathrm{ml})$, culture supernatants were harvested and analyzed for the production of IL-1 $\beta$ (A), IL-2 (B), LL-6 (C), IL-10 (D), TGF- $\beta 1$ (E), TGF- $\beta 2$ (F), TNF- $\alpha(G)$, and INF- $\gamma(H)$ by ELISA. Data are presented as mean \pm S.D. of 3 independent experiments. ${ }^{\star} P<0.05$ compared with 0 hr.

tion at $24 \mathrm{hr}$ was also 3 -fold higher than that of ESPs, whereas the levels of IL-1 $\beta$ and IL-6 secretion were almost the same as those of ESPs. These results indicate that CsTrip, CsLeg, and
CsGrb2 function as strong inducers for the production of TGF- $\beta$ and TNF- $\alpha$ in HuCCT1 cells. 
A
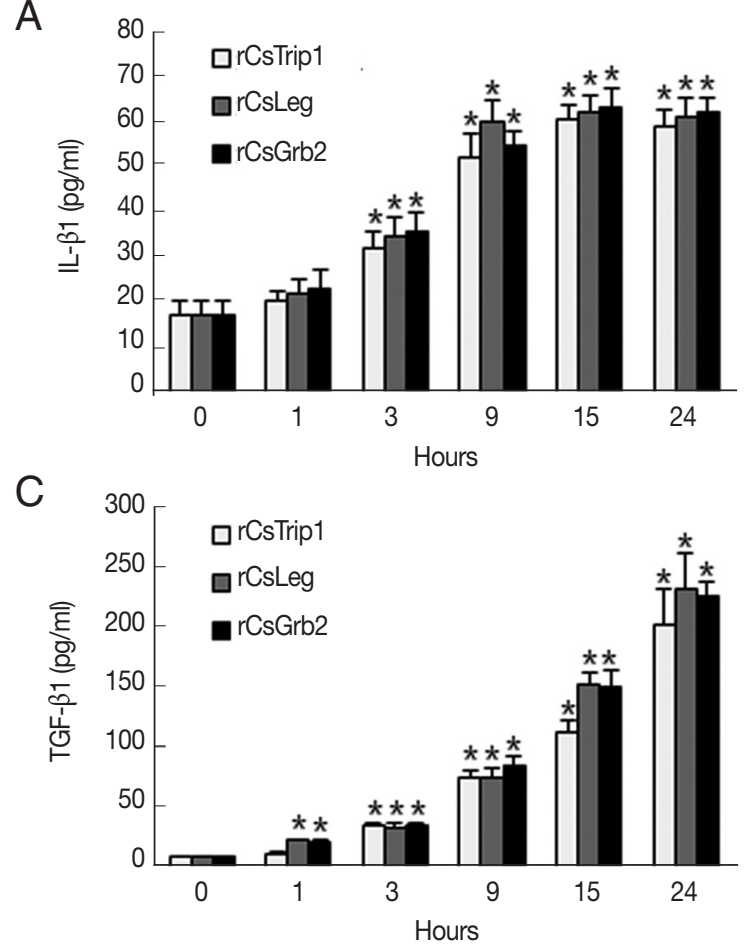

E

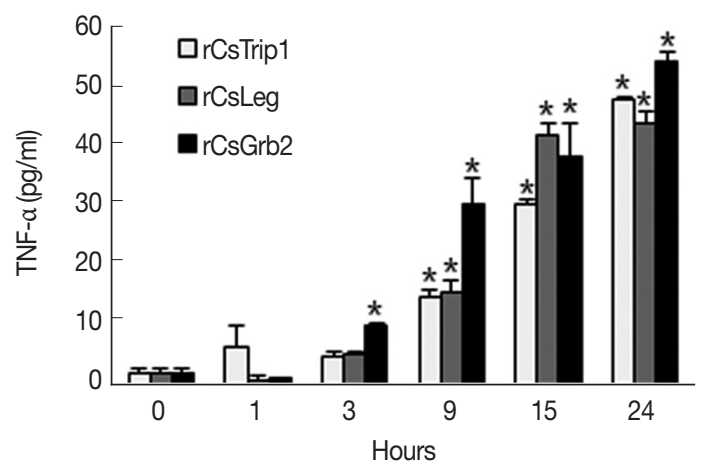

DISCUSSION

Major pathological consequences of liver fluke infection are the persistent irritation and chronic inflammation of the bile duct epithelium and bile contamination via direct contact with worms and their ESPs. These play key roles in the initiation, propagation and development of more severe hepatobiliary diseases, including hepatomegaly, cholangitis, cholecystitis, cholelithiasis, and cholangiocarcinoma [19]. We previously reported that exposure of HuCCT1 cells to C. sinensis ESPs triggered enzymatic free radical generation, leading to NF-kBmediated inflammatory process [8]. Herein, we provide evidence that the ESPs function as foreign peptides, provoking host cellular immune responses such as the stimulation of in-
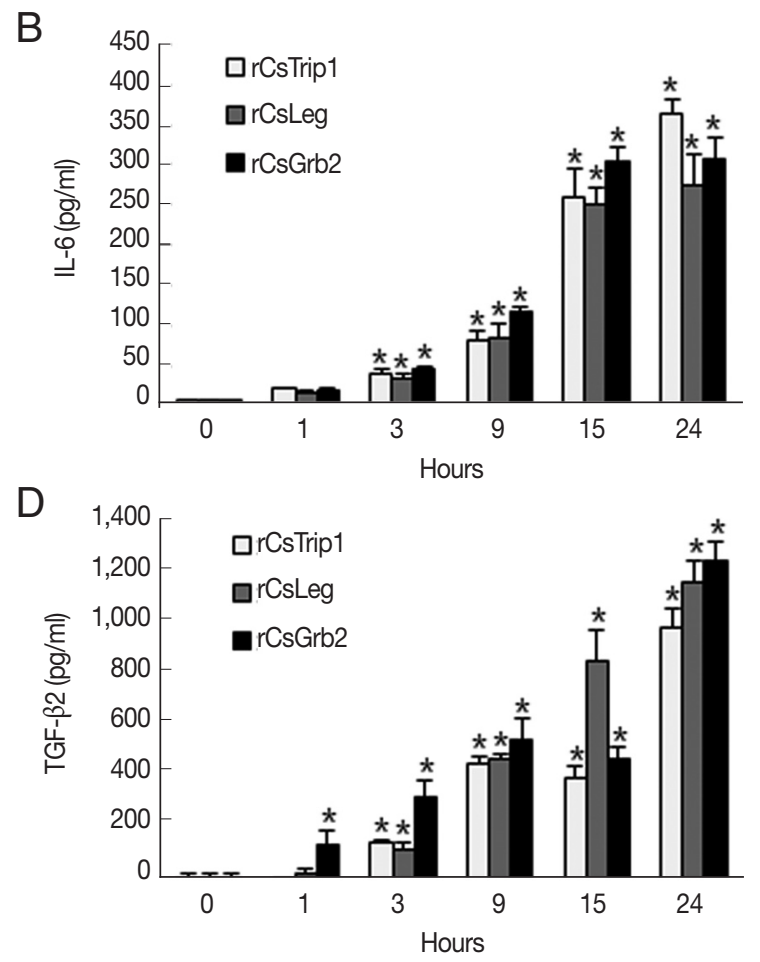

Fig. 3. Differential expressions of IL-1 $\beta$, IL-6, TGF- $\beta 1$, TGF- $\beta 2$, and TNF- $\alpha$ in recombinant $C$. sinensis protein-treated HuCCT1 cells. Cells were treated with $2 \mu \mathrm{g} / \mathrm{ml}$ of CsTrip1, CsLeg, or CsGrb2 proteins for 0-24 hr, and the production of IL-1 $\beta$ (A), IL-6 (B), TGF- $\beta 1$ $(\mathrm{C})$, TGF- $\beta 2(\mathrm{D})$, and TNF- $\alpha(\mathrm{F})$ in culture supernatants was determined by ELISA. Data are presented as mean \pm S.D. of 3 independent experiments. ${ }^{*} P<0.05$ compared with $0 \mathrm{hr}$.

flammatory cytokine production.

In addition to the ESPs, 3 antigenic proteins of $C$. sinensis were employed to examine their immunopathological roles in host cells. Based on a comparison with mammalian homologues, CsTrip1 is characterized as a member of the WD-repeat family of proteins with dual functions, a modulator in the TGF- $\beta$ signaling pathway and a subunit of the eukaryotic translation initiation factor 3. Analysis of deduced amino acid sequences revealed that CsTrip1 did not contain any target sequences for subcellular location, but its expression in the tegument and the existence of predicted linear B cell epitopes suggests that this protein may be secreted through non-classical pathways [17]. CsLeg was reported to be a secreted protein, as assessed by immuno-proteomic analysis of ESPs from adult 
worms. It exhibits cysteine protease activity and is considered a serodiagnostic antigen against clonorchiasis pathogens [12]. CsGrb2 is a homologue of mammalian growth factor receptorbound protein 2 with one SH2 domain flanked by $2 \mathrm{SH} 3$ domains, playing an important role in Ras-mediated signal transduction pathways as an adaptor protein. Its abundant expression in the oral sucker of adult worms and the immunoreactivity of recombinant protein with infected sera imply that CsGrb2 may be exported to the host interface [16].

Cytokines are secreted by various types of cell which orchestrate the host physiological processes and mediate cell-to-cell communication. They possess the ability to either promote or aggregate inflammation or to attenuate inflammatory responses. It has been reported that concanavalin A-stimulated splenocytes from 2 mouse strains (BALB/C and FVN/NJ) with different susceptibility show distinct Th1 and Th2 cytokine responses to C. sinensis infection; the levels of Th1 cytokines (IFN- $\gamma$ and IL-2) from both strains decrease between 2 and 4 weeks post-infection, whereas Th2 cytokines (IL-4, IL-5, and IL-10) increase, suggesting that susceptibility or resistance to the infection may be associated with Th2 cytokine production [20]. Production of inflammatory cytokines from the livers of hamsters infected with C. sinensis were markedly elevated [21]. Also, the serum levels of proinflammatory cytokines such as TNF- $\alpha$, IL-1 $1 \beta$, and IL-6 in C. sinensis-infected mice were differentially regulated during the period of infection [22]. The present study showed that ESP treatment stimulated both pro- and anti-inflammatory cytokines (IL-1 $\beta$, IL- 6 , and TNF- $\alpha$ vs IL-10 and TGF- $\beta$ ) in HuCCT1 cells, whereas the release of IL-2 and IFN- $\gamma$ was negligible (Fig. 2). This is consistent with previous reports of IL-10 and TGF- $\beta$ elevation in a $C$. sinensis crude antigen-treated murine macrophage RAW264.7 cell line via the ERK signaling cascade [23], Toll-like receptor 4 (TLR4)-mediated TNF-a induction in C. sinensis ESP-treated primary mouse intrahepatic biliary epithelial cells [24], TLR4/NF-kB-dependent IL-6 and IL-8 induction in an O. viverrini ESP-treated human cholangiocyte cell line [25], and increased IL-1 $\beta$ and TNF- $\alpha$ secretion in peripheral blood mononuclear cells (PBMC) co-cultivated with adult $O$. viverrini [26]. Taken together, these findings indicate that liver fluke ESPs sequentially enhance the expression of inflammatory cytokines in diverse host cells, contributing to the immunopathogenesis of clonorchiasis or opisthorchiasis.

Liver fluke proteins have been reported to play diverse pathophysiologic roles in host cells, including the modulation of TGF- $\beta 1$-mediated fibrosis, oxidative stress-induced apoptosis, and the promotion of wound healing [27-29]. In this study, recombinant C. sinensis protein (CsTrip1, CsLeg, or CsGrb2) treatment resulted in increased secretion of inflammatory cytokines such as IL- $1 \beta$, IL- 6 , TGF- $\beta$, and TNF- $\alpha$ in HuCCT1 cells in a time-dependent manner. The levels of TGF- $\beta$ and TNF- $\alpha$ secretion were predominant in comparison to those of IL-1 $\beta$, and IL- 6 ; the former exhibited increases many times higher than those for ESP treatment while the latter resulted in levels similar to those for ESPs (Fig. 3). We observed that the levels of cytokine secretion were elevated with protein concentrations between 1 and $5 \mu \mathrm{g} / \mathrm{ml}$, while treatment with higher concentrations $(<10 \mu \mathrm{g} / \mathrm{ml})$ reduced cell viability (data not shown). Because of contrasting roles of TGF- $\beta$ and TNF- $\alpha$ in both proliferation and cell death dependent on cell type, contents, and the mutual microenvironment [2,11], it is tempting to speculate that their excess production induced by each Cs protein could synergistically contribute to an increase in cytotoxicity.

The immune response network employs cytokine secretion as part of the host defense against liver fluke infection. We noted that the ESP treatment induced the secretion of anti-inflammatory cytokines such as IL-10 and TGF- $\beta$ but, induced no obvious change in the levels of IL-2 and IFN- $\gamma$, suggesting that the proinflammatory cytokines might be suppressed by anti-inflammatory cytokines. Consistent with this finding, parasite-specific PBMC-derived IFN- $\gamma$ and IL-4 production has been shown to be restrained by IL-10 and TGF- $\beta$ in experimental bovine fasciolosis. The results from this study imply that a combination of IL-10 and TGF- $\beta$ may play a role in controlling host immune responses (the switch from an acute to a chronic infection stage), thereby generating protective immunity to the worm for growth and survival [30]. Although inflammatory cytokine production acts as a host defense mechanism against infection or injury, aberrant regulation leads to severe chronic disorders including carcinogenesis. Constitutive and dysregulated production of IL-1 $\beta$ and TNF- $\alpha$ is attributed to inflammation-associated tissue damage, and subsequent tumor promotion and progression [31,32]. Elevated plasma levels of IL-6 have been reported to be closely related to increased risk of $O$. viverrini-associated advanced periductal fibrosis and cholangiocarcinoma in a dose-dependent manner, suggesting that IL-6 plays a key role in hepatobiliary pathogenesis [33]. In addition to TGF- $\beta /$ Smad signaling pathway-mediated hepatic fibrosis in mice with clonorchiasis [34], exposure to IL-6 and 
TGF- $\beta 1$ induces endogenous production of IL- 6 and TGF- $\beta 1$ in biliary tract cancer cells through positive crosstalk loop, conferring enhanced malignant features such as epithelialmesenchymal transition, invasion, and chemoresistance [35].

In conclusion, the present study shows that $C$. sinensis ESPs and their putative protein components differentially induce the secretion of inflammatory cytokines, providing evidence for an immunopathological role for ESPs in host cells. In the context of chronic clonorchiasis-associated hepatobiliary abnormalities, constitutive dysregulation of inflammatory cytokines may enhance the more aggressive pathologic process in the bile duct and its surrounding liver tissues, leading to cholangiocarcinogenesis. Further study is warranted to elucidate the signal transduction pathways mediated by $C$. sinensis-driven proteins in host cells that underlie the pathologic mechanisms of parasite-host interaction during clonorchiasis progression.

\section{ACKNOWLEDGMENTS}

This study was supported by a National Research Foundation of Korea funded by the Ministry of Education (No. 2016R1D 1A1A02937406) and the Korea National Institute of Health, Ministry of Health and Welfare, Korea (2011E5401100) and this research was supported by the Chung-Ang University research grant in 2018.

\section{CONFLICT OF INTEREST}

The authors declare no conflict of interest related to this study.

\section{REFERENCES}

1. Inclan-Rico JM, Siracusa MC. First Responders: Innate Immunity to Helminths. Trends Parasitol 2018; 34: 861-880.

2. Landskron G, De la Fuente M, Thuwajit $P$, Thuwajit $C$, Hermoso MA. Chronic inflammation and cytokines in the tumor microenvironment. J Immunol Res 2014; 2014: 149185.

3. Hong ST, Fang Y. Clonorchis sinensis and clonorchiasis, an update. Parasitol Int 2012; 61: 17-24.

4. Kim TS, Pak JH, Kim JB, Bahk YY. Clonorchis sinensis, an oriental liver fluke, as a human biological agent of cholangiocarcinoma: a brief review. BMB Rep 2016; 49: 590-597.

5. Qian MB, Utzinger J, Keiser J, Zhou XN. Clonorchiasis. Lancet 2016; 387: 800-810.

6. Bouvard V, Baan R, Straif K, Grosse Y, Secretan B, El Ghissassi F,
Benbrahim-Tallaa L, Guha N, Freeman C, Galichet L, Cogliano $\mathrm{V}$. A review of human carcinogens--Part B: biological agents. Lancet Oncol 2009; 10: 321-322.

7. Kim YJ, Choi MH, Hong ST, Bae YM. Proliferative effects of excretory/secretory products from Clonorchis sinensis on the human epithelial cell line HEK293 via regulation of the transcription factor E2F1. Parasitol Res 2008; 102: 411-417.

8. Nam JH, Moon JH, Kim IK, Lee MR, Hong SJ, Ahn JH, Chung JW, Pak JH. Free radicals enzymatically triggered by Clonorchis sinensis excretory-secretory products cause NF-kappaB-mediated inflammation in human cholangiocarcinoma cells. Int J Parasitol 2012; 42: 103-113.

9. Pak JH, Kim DW, Moon JH, Nam JH, Kim JH, Ju JW, Kim TS, Seo SB. Differential gene expression profiling in human cholangiocarcinoma cells treated with Clonorchis sinensis excretory-secretory products. Parasitol Res 2009; 104: 1035-1046.

10. Pak JH, Moon JH, Hwang SJ, Cho SH, Seo SB, Kim TS. Proteomic analysis of differentially expressed proteins in human cholangiocarcinoma cells treated with Clonorchis sinensis excretory-secretory products. J Cell Biochem 2009; 108: 1376-1388.

11. Chaiyadet S, Smout M, Johnson M, Whitchurch C, Turnbull L, Kaewkes S, Sotillo J, Loukas A, Sripa B. Excretory/secretory products of the carcinogenic liver fluke are endocytosed by human cholangiocytes and drive cell proliferation and IL6 production. Int J Parasitol 2015; 45: 773-781.

12. Ju JW, Joo HN, Lee MR, Cho SH, Cheun HI, Kim JY, Lee YH, Lee KJ, Sohn WM, Kim DM, Kim IC, Park BC, Kim TS. Identification of a serodiagnostic antigen, legumain, by immunoproteomic analysis of excretory-secretory products of Clonorchis sinensis adult worms. Proteomics 2009; 9: 3066-3078.

13. Wang C, Lei H, Tian Y, Shang M, Wu Y, Li Y, Zhao L, Shi M, Tang X, Chen T, Lv Z, Huang Y, Tang X, Yu X, Li X. Clonorchis sinensis granulin: identification, immunolocalization, and function in promoting the metastasis of cholangiocarcinoma and hepatocellular carcinoma. Parasit Vectors 2017; 10: 262.

14. Smout MJ, Laha T, Mulvenna J, Sripa B, Suttiprapa S, Jones A, Brindley PJ, Loukas A. A granulin-like growth factor secreted by the carcinogenic liver fluke, Opisthorchis viverrini, promotes proliferation of host cells. PLoS Pathog 2009; 5: e1000611.

15. Suttiprapa S, Matchimakul P, Loukas A, Laha T, Wongkham S, Kaewkes S, Brindley PJ, Sripa B. Molecular expression and enzymatic characterization of thioredoxin from the carcinogenic human liver fluke Opisthorchis viverrini. Parasitol Int 2012; 61: 101106.

16. Bai X, Lee JY, Kim TI, Dai F, Lee TJ, Hong SJ. Molecular cloning and characterization of growth factor receptor bound-protein in Clonorchis sinensis. PLoS One 2014; 9: e85577.

17. Hu X, Zhou H, Hu F, Xu J, Zhao Y, Yu X. Recognition and characterization of TGF-beta receptor interacting protein 1 (TRIP-1) containing WD40 repeats from Clonorchis sinensis by bioinformatics, cloning, and expression in Escherichia coli. Parasitol Res 2008; 103: 1151-1158.

18. Yoo WG, Kim DW, Ju JW, Cho PY, Kim TI, Cho SH, Choi SH, 
Park HS, Kim TS, Hong SJ. Developmental transcriptomic features of the carcinogenic liver fluke, Clonorchis sinensis. PLoS Negl Trop Dis 2011; 5: e1208.

19. Vennervald BJ, Polman K. Helminths and malignancy. Parasite Immunol 2009; 31: 686-696.

20. Choi YK, Yoon BI, Won YS, Lee CH, Hyun BH, Kim HC, Oh GT, Kim DY. Cytokine responses in mice infected with Clonorchis sinensis. Parasitol Res 2003; 91: 87-93.

21. Choi W, Chu J. The characteristics of the expression of heat shock proteins and COX-2 in the liver of hamsters infected with Clonorchis sinensis, and the change of endocrine hormones and cytokines. Folia Parasitol (Praha) 2012; 59: 255-263.

22. Maeng S, Lee HW, Bashir Q, Kim TI, Hong SJ, Lee TJ, Sohn WM, $\mathrm{Na}$ BK, Kim TS, Pak JH. Oxidative stress-mediated mouse liver lesions caused by Clonorchis sinensis infection. Int J Parasitol 2016; 46: 195-204.

23. Wi HJ, Jin Y, Choi MH, Hong ST, Bae YM. Predominance of IL10 and TGF-beta production from the mouse macrophage cell line, RAW264.7, in response to crude antigens from Clonorchis sinensis. Cytokine 2012; 59: 237-244.

24. Yan C, Wang YH, Yu Q, Cheng XD, Zhang BB, Li B, Zhang B, Tang RX, Zheng KY. Clonorchis sinensis excretory/secretory products promote the secretion of TNF-alpha in the mouse intrahepatic biliary epithelial cells via Toll-like receptor 4. Parasit Vectors 2015; 8: 559.

25. Ninlawan K, O'Hara SP, Splinter PL, Yongvanit P, Kaewkes S, Surapaitoon A, LaRusso NF, Sripa B. Opisthorchis viverrini excretory/secretory products induce toll-like receptor 4 upregulation and production of interleukin 6 and 8 in cholangiocyte. Parasitol Int 2010; 59: 616-621.

26. Hongsrichan N, Intuyod K, Pinlaor P, Khoontawad J, Yongvanit P, Wongkham C, Roytrakul S, Pinlaor S. Cytokine/chemokine secretion and proteomic identification of upregulated annexin A1 from peripheral blood mononuclear cells cocultured with the liver fluke Opisthorchis viverrini. Infect Immun 2014; 82: 21352147.

27. Zhou L, Shang M, Shi M, Zhao L, Lin Z, Chen T, Wu Y, Tang Z, Sun H, Yu J, Huang Y, Yu X. Clonorchis sinensis lysophospholi- pase inhibits TGF-beta1-induced expression of pro-fibrogenic genes through attenuating the activations of Smad3, JNK2, and ERK1/2 in hepatic stellate cell line LX-2. Parasitol Res 2016; 115: 643-650.

28. Matchimakul P, Rinaldi G, Suttiprapa S, Mann VH, Popratiloff A, Laha T, Pimenta RN, Cochran CJ, Kaewkes S, Sripa B, Brindley PJ. Apoptosis of cholangiocytes modulated by thioredoxin of carcinogenic liver fluke. Int J Biochem Cell Biol 2015; 65: 72-80.

29. Smout MJ, Sotillo J, Laha T, Papatpremsiri A, Rinaldi G, Pimenta RN, Chan LY, Johnson MS, Turnbull L, Whitchurch CB, Giacomin PR, Moran CS, Golledge J, Daly N, Sripa B, Mulvenna JP, Brindley PJ, Loukas A. Carcinogenic parasite secretes growth factor that accelerates wound healing and potentially promotes neoplasia. PLoS Pathog 2015; 11: e1005209.

30. Flynn RJ, Mulcahy G. The roles of IL-10 and TGF-beta in controlling IL-4 and IFN-gamma production during experimental Fasciola hepatica infection. Int J Parasitol 2008; 38: 1673-1680.

31. Apte RN, Voronov E. Interleukin-1--a major pleiotropic cytokine in tumor-host interactions. Semin Cancer Biol 2002; 12: 277290.

32. Szlosarek P, Charles KA, Balkwill FR. Tumour necrosis factor-alpha as a tumour promoter. Eur J Cancer 2006; 42: 745-750.

33. Sripa B, Thinkhamrop B, Mairiang E, Laha T, Kaewkes S, Sithithaworn P, Periago MV, Bhudhisawasdi V, Yonglitthipagon P, Mulvenna J, Brindley PJ, Loukas A, Bethony JM. Elevated plasma IL-6 associates with increased risk of advanced fibrosis and cholangiocarcinoma in individuals infected by Opisthorchis viverrini. PLoS Negl Trop Dis 2012; 6: e1654.

34. Yan C, Wang L, Li B, Zhang BB, Zhang B, Wang YH, Li XY, Chen JX, Tang RX, Zheng KY. The expression dynamics of transforming growth factor-beta/Smad signaling in the liver fibrosis experimentally caused by Clonorchis sinensis. Parasit Vectors 2015; 8: 70.

35. Yamada D, Kobayashi S, Wada H, Kawamoto K, Marubashi S, Eguchi H, Ishii H, Nagano H, Doki Y, Mori M. Role of crosstalk between interleukin- 6 and transforming growth factor-beta 1 in epithelial-mesenchymal transition and chemoresistance in biliary tract cancer. Eur J Cancer 2013; 49: 1725-1740. 
